\title{
Androgens and Hypertension in Men and Women: a Unifying View
}

\author{
Costanzo Moretti ${ }^{1}$ - Giulia Lanzolla ${ }^{2}$ - Marta Moretti $^{3} \cdot$ Lucio Gnessi $^{2}$ • \\ Enrico Carmina ${ }^{4}$
}

Published online: 28 April 2017

(C) Springer Science+Business Media New York 2017

\begin{abstract}
Purpose of Review This review was designed to revaluate the androgen role on the mechanisms of hypertension and cardiovascular risks in both men and women. Sex steroids are involved in the regulation of blood pressure, but pathophysiological mechanism is not well understood. Androgens have an important effect on metabolism, adipose and endothelial cell function, and cardiovascular risk in both men and women. A focal point in this contest is represented by the possible genderspecific regulation of different tissues and in particular of the adipose cell. Available data confirm that androgen deficiency is linked to increased prevalence of hypertension and cardiovascular diseases. Adipocyte dysfunction seems to be the main involved mechanism. Androgen replacement reduces inflammation state in man, protecting by metabolic syndrome progression. In women, androgen excess has been considered as promoting factor of cardiovascular risk. However, recent data suggest that excessive androgen production has little effect per se in inducing hypertension in young women of reproductive
\end{abstract}

This article is part of the Topical Collection on Hypertension and Metabolic Syndrome

Enrico Carmina

enrico.carmina@ae-society.org

1 UOC of Endocrinology and Diabetes, TorVergata University of Rome, Reproductive Endocrinology Section, San Giovanni Calibita Fatebenefratelli Hospital, Rome, Italy

2 Department Experimental Medicine-Medical Physiopathology, Food Science and Endocrinology Section, "Sapienza" University of Rome, Rome, Italy

3 Laboratory of Molecular Oncology, Department of Molecular Medicine, "Sapienza" University of Rome, Rome, Italy

4 Department of Health Sciences and Mother and Child Care, University of Palermo, Palermo, Italy age. Also in postmenopausal women, data on relative androgen excess and hypertension are missing, while adrenal androgen deficiency has been associated to increased mortality. Recent Findings Molecular mechanisms linking androgen dysregulation to hypertension are almost Unknown, but they seem to be related to increased visceral fat, promoting a chronic inflammatory state through different mechanisms. One of these may involve the recruitment and over-activation of NF-kB, a ubiquitous transcription factor also expressed in adipose cells, where it may cause the production of cytokines and other immune factors. The NF-kB signalling pathway may also influence brown adipogenesis leading to the preferential enlargement of visceral adipocytes. Chronic inflammation and adipocyte dysfunction may alter endothelial function leading to hypertension. Summary Both in men and in women, particularly in the postmenopausal period, hypoandrogenism seems to be a major determinant of the increased prevalence of hypertension. The relationship between androgen signalling and NF-kB might explain the pathophysiological mechanism leading to the development of endothelium dysfunction and hypertension.

Keywords Androgens · Androgen receptor - Adipokines · NF-kappaB · Endothelial dysfunction · Metabolic syndrome · Cardiovascular disease $\cdot$ Hypertension $\cdot$ Obesity $\cdot$ Brown adipose tissue $\cdot$ PCOS

\section{Introduction}

In the last few years, interest in the role played by sex gender on the regulation of metabolic homeostasis, blood pressure, and cardiovascular disease (CVD) has been growing. Men typically develop CVD earlier than women [1]. The sexual dimorphism begins at the time of puberty and continues through the adult age 
until post-menopause, when women have higher blood pressure than age-matched men [2-4, 5•].

In this short review, we will focus on the possible different effects by sex of androgens on hypertension. It has been reported that this sexual dimorphism may depend on different responses in men and women to androgens. However, recent evidence suggests that the effects of androgens on hypertension may be similar in males and females. Finally, we will review the mechanisms by which androgens may determine hypertension. In particular, we will discuss new information showing an important interaction of androgens with factors involved in endoplasmic reticulum (ER) oxidative stress and $\mathrm{NF}-\mathrm{kB}$ activation, which play pivotal roles in the pathogenesis of metabolic syndrome and by this way may induce hypertension [6-9]. Moreover, the ability of androgens to modulate endothelial cell function, through genomic or non-genomic signaling pathways, will be examined [10].

\section{Androgens and Hypertensive Risk in Males}

A direct effect of androgens on promoting hypertension has been hypothesized [1]. Animal studies suggested that androgens could promote hypertension by stimulating sodium reabsorption via the proximal tubule of the kidney [11] or by increasing angiotensinogen synthesis in the kidney [12, 13]. Consistent with that, it was reported that androgens probably stimulate oxidative stress and increase endothelin production, thereby promoting renal vasoconstriction [14] and resulting in hypertension in men but not in women [15].

However, in the last few years, several studies have shifted attention to the effect of low androgen levels on hypertension. In fact, it has been demonstrated that men with free testosterone levels in the lowest quartile had a $24 \%$ greater risk for allcause mortality due to ischemic heart disease [16]. Specifically, in old men, total testosterone levels are inversely associated with systolic blood pressure and increased risk of death over the subsequent 20 years, independently from other risk factors and pre-existing health conditions [17]. Furthermore, lower testosterone levels predict cardiovascular events in older men, such as stroke and transient ischemic attack, and are associated with higher cardiovascular and overall mortality. Androgen levels are actually decreased in men with chronic diseases, including hypertension, obesity, heart disease, chronic kidney disease, and metabolic syndrome [18].

These findings have led to the proposition that in middleaged and older men, lower testosterone levels are associated with conditions that predispose to CVD, such as hypertension [19]. Many investigators have suggested that lower testosterone blood levels are not just a consequence of the chronic disease but actually contribute to disease progression [20]. In addition, androgen replacement reduces systolic and diastolic blood pressure [21-23], while androgen therapy worsens hypertension and CVD risk in men with no testosterone deficiency [24]. Finally, it has been shown that androgens increase blood pressure in hypertensive non obese rats. [25].

Overall, these data suggest that in men, androgen deficiency may worsen cardiovascular physiology by several mechanisms. One of these effects is the increase in blood pressure.

\section{Hypoandrogenism, Blood Hypertension, and Metabolic Syndrome in men}

Several studies have demonstrated a link between androgen deficiency, hypertension, and metabolic syndrome. It has been hypothesized that hypogonadism may increase hypertension risk by promoting metabolic syndrome (MetS). In fact, androgen deficiency is particularly common in men with MetS [26••], and hypoandrogenism may be an additional feature of this disease [27•]. Finally, men with prostate cancer who undergo long-term androgen deprivation therapy have significantly higher rates of MetS [28, 29••, 30].

The nature of the link between androgen deficiency and MetS is likely to be multifactorial and different among individuals. Diminished testosterone synthesis may be determined by metabolic syndrome through several mechanisms, including a low-grade inflammatory state and increased visceral fat, both important features of MetS. Androgens have anti-inflammatory activity, and hypogonadal men treated with androgen replacement exhibit a significant reduction in inflammatory cytokine levels [31]. It is also known that visceral adiposity may reduce sex hormone binding globulin levels and luteinizing hormone (LH) amplitude, thereby influencing bioavailable testosterone in obese men. Indeed, abdominal obesity has been associated with low testosterone (T) in both cross-sectional and longitudinal studies, and low $\mathrm{T}$ concentration correlates with greater visceral fat accumulation. Increased central fat depots may contribute to hypogonadism through increased aromatase activity, resulting in a higher conversion of T to estradiol (E2) [32]. Fat cells also synthesize leptin and inflammatory cytokines, which have been inversely associated with testosterone levels, perhaps through an inhibitory effect on the production of LH [33].

On the other hand, androgen deficiency may directly contribute to obesity and development of MetS by promoting the production of fat cells. Testosterone promotes lipolysis and reduces fatty acid synthesis, and animal models have shown that $\mathrm{T}$ deficiency decreases lipolysis [34॰•].

Thus, the available evidence strongly suggests that in men, there is a strict bidirectional relationship between fat accumulation and $\mathrm{T}$ deficiency [35], and this may be a major mechanism by which androgens influence blood pressure. 


\section{Hyperandrogenism and Hypertension Risk in Young Women with Polycystic Ovarian Syndrome}

Young women typically have a lower hypertension rate than age-matched men [36]. The sex differences in blood pressure control may be explained by the different hormonal status but mainly by the presence in young women of elevated estrogen levels that protect against endothelial dysfunction and CVD. It is known that $\mathrm{E} 2$ has vasodilator function by increasing endothelial nitric oxide synthase [37] and angiotensin converting enzyme 2 (ACE2) and down-regulating ACE and AT1 receptor [38]. Estradiol is also a modest antioxidant [15]. Moreover, animal studies suggest that estrogens protect against hypertension by reducing sympathetic outflow [39].

A higher prevalence of hypertension in young women with elevated androgen levels has been reported and could suggest that elevated androgens induce an increased risk for hypertension [40 $]$. However, data from women with polycystic ovary syndrome (PCOS), the most common cause of androgen excess in women, seem to indicate a different pathogenesis of hypertension in these subjects. PCOS is a complex disorder that is often associated with metabolic alterations of insulin resistance, increased susceptibility to type 2 diabetes, central obesity, and elevated CVD risk [41]. Prevalence of hypertension in young PCOS women aged 18-35 years is increased (7.3\% of patients with the classic severe form) and is higher than that reported in the general female population of similar age $[42,43 \bullet]$. Thus, analogously on what happens in men (24), in women, a link between androgen excess and blood pressure dysregulation has been proposed.

However, most evidence suggests that in PCOS, the elevated hypertension risk is determined by the metabolic alterations. In fact, PCOS is a very heterogeneous disorder with different subgroups of patients with different prevalence of hypertension $[44,45]$. All data reporting increased prevalence of hypertension refer to patients with the severe phenotype (classic PCOS or phenotype A and B) that is associated with insulin resistance and central obesity. Patients with mild phenotypes (phenotypes $\mathrm{C}$ and $\mathrm{D}$ ) do not have an increased risk of hypertension [45]. In particular, PCOS patients with phenotype $\mathrm{C}$ have increased androgen production but no increased prevalence of hypertension. Interestingly, these same patients have a low prevalence of insulin resistance and MetS and have a body weight lower than PCOS patients with the classic phenotype [45].

It may be concluded that in PCOS, the increased risk of hypertension is linked to the metabolic dysfunction with mechanisms that may be similar to that found in hypogonadal men. The adipocyte dysfunction likely plays a pivotal role in the relationship between hyperandrogenemia and CVD risk [19]. In fact, an important hallmark of PCOS women with the severe phenotype is the excess of visceral adipose cells that increase the release of inflammatory cytokines and decrease production of adiponectin, thereby promoting endothelial dysfunction and hypertension [46]. The adiponectin/leptin and adiponectin/resistin ratios may predict MetS and hypertension in women with PCOS [47•].

Overall, in young women, androgens have a small role per se in increasing blood pressure and may participate in the pathogenesis of hypertension only by contributing to insulin resistance and/or adipocyte excess and dysfunction. On the other hand, hyperinsulinemia and adipocyte dysfunction further increase androgen levels, promoting a vicious cycle which ensures an inflammatory state, MetS, and increased CVD risk.

\section{Androgens and Hypertension in Postmenopausal Women}

The sexual dimorphism on blood pressure control begins at puberty and persists until after menopause, when women have higher blood pressure than age-matched men. The incidence of CVD-related deaths is generally higher in women than men $[48,49]$, and in Europe, as in the rest of the world, $25 \%$ of postmenopausal women are hypertensive [50].

Postmenopausal changes in estrogen/androgen ratio that induce a relative androgen excess have been proposed as important factors in the higher prevalence of hypertension [36] in older women. Initial studies reported that both E2 and T production decrease after menopause, but $\mathrm{T}$ increases progressively until 70 years of age, when androgen production is similar to that of premenopausal women [51].

However, the concept of a relative hyperandrogenism in postmenopausal women has been challenged by a better understanding of adrenal and ovarian androgen secretion. Adrenal androgens start decreasing by the age of 25-30 years, and in postmenopausal women, their levels are at least 50\% lower than in reproductive women of younger age [52]. Ovarian androgens start decreasing later at an age of 3540 years and during the postmenopausal period are about $30 \%$ lower than in young reproductive age [53-55] More studies are needed to better explain hypertension prevalence in postmenopausal women, but it has to be remembered that in aging women, as in men, very low dehydroepiandrosterone sulfate (a main adrenal androgen) levels have been associated with increased mortality [56••].

Quite possibly, the relative deficiency of estrogen that is observed after menopause participates in metabolic dysfunction and deposition of visceral (and ectopic) fat that is observed after menopause. In some ways, these phenomena are more evident in women than in men because of the important effect of estrogen reduction. 


\section{Androgen Deficiency, Metabolically Active Obesity, and Hypertension}

As we have discussed, androgens exhibit beneficial effects on cardiovascular function, and growing evidence suggests that this non-classic effect of androgens is largely mediated by the prevention of adipocyte dysfunction. As we have reviewed in a previous paper [19], adipocyte dysfunction probably represents the main mechanism inducing the endothelial alterations that are typical of hypertension and cardiovascular diseases of obese subjects.

While liver accumulation of free fatty acids (FFA) released by visceral fat is generally considered the main determinant of insulin resistance in obesity, other mechanisms, and in particular dysfunctional regulation of adipokines, may be equally or more important to explain insulin resistance in the obese state.

In this process, the reduction of adiponectin levels seems to play an essential role. Because adiponectin is mainly produced in the subcutaneous fat [57], it has been hypothesized that increased production of cytokines inside the visceral and ectopic fat is the mechanism that inhibits subcutaneous production of adiponectin. The process may be initiated by increased death of adipose cells consequent to excessive enlargement of visceral and intramuscular adipose cells. It is followed by colonization and activation of macrophages and by increased production of several inflammatory factors mainly cytokines but also some adipokines (resistin, visfatin) [19].

Other adipokine changes are part of the adipocyte dysfunction and may be particularly important for inducing hypertension. In particular, increased leptin may induce hypertension by promoting sympathetic nervous system overactivity while reduced omentin may have a permissive role on atherogenesis.

\section{Molecular Mechanisms Linking Androgen Deficiency to Hypertension. The Role of the Interaction Between Androgen Receptor and NF-kB}

The molecular mechanisms linking androgen deficiency to adipocyte dysfunction are largely unknown. However, two main mechanisms may be hypothesized.

Because most hypogonadic men and women have increased adipose tissue mainly in visceral and intramuscular locations, it may be thought that in conditions of excessive energy supply, androgens promote adipocyte multiplication in subcutaneous regions while in conditions of androgen deficiency, lipids are accumulated mainly in visceral areas by an increased in the size of adipocytes. Excessive adipocyte size may be followed by increased cellular death, macrophage activation, and cytokine production. The final consequence is obesity, chronic inflammation, and atherogenesis.
Fig. 1 Effect of androgen deficiency on increasing risk of metabolic syndrome and cardiovascular disease. Both in men and in postmenopausal women, when the protective estrogen effect is reduced, androgen deficiency contributes to enlarge the size of visceral fat because of increased lipid accumulation in adipocytes, which in turn causes cellular death followed by macrophage activation, cytokine production, and endothelial dysfunction. NF- $\mathrm{KB}$ role in this process is depicted (see text). AGT angiotensinogen, FFAs free fatty acids, ICAM-1 intracellular adhesion molecule-1, $I L-6$ interleukin- $6, I L-1 \beta$ interleukin-1 beta, $J N K s$ c-Jun N-terminal kinases, $M 1$ macrophages macrophages that encourage inflammation, $p 38 M A P K / M P K / E R K$ mitogen-activated protein kinases/extracellular signal-regulated kinases pathway, $M C P-1$ monocyte chemoattractant protein-1, MIP-1 macrophage inflammatory protein-1, NF- $k B$ nuclear factor-kappa light-chain-enhancer of activated B cells, SIRT1 NAD-dependent deacetylase Sirtuin-1, TNF $\alpha$ tumor necrosis factor-alpha, VCAM-1 vascular cell adhesion protein-1

However, androgen deficiency may promote inflammatory and immune responses inside adipose tissue by alternative mechanisms. In fact, it has been shown that androgen receptor (AR) deficient mice have higher blood pressure compared to wild type [58]. The AR seems to interact with several factors having an important role in the regulation of immune and inflammatory response and in cell growth and differentiation.

One of these factors, nuclear factor $\mathrm{kB}(\mathrm{NF}-\mathrm{kB})$ [59-61], is a dimer composed of nearly all combinations of the NF- $\kappa B$ family members p65/RelA, RelB, c-Rel, NF-kB1/p50, or NF-kB2/p52 and expressed as RelA/p50 heterodimeric complex in many tissues but mainly in liver and adipose cells [62••]. NF-kB (see Fig. 1) may play an important role in the inflammatory activation and progression caused by adipocyte dysfunction [63]. NF-kB along with other factors like p38MAPK and ERK1/2 has an important role in regulating immune responses inside the adipose cells $[62 \bullet \cdot$. Activation of the NF-kB signaling pathway may also determine dysregulation in the liver and central nervous system (CNS), as the mediobasal hypothalamus controls energy balance, appetite regulation, and food intake. IKK $\beta$, one of the most important activators of NF-kB, is constitutively expressed in the CNS of mice exposed to a high-fat diet, blocking leptin and insulin signaling and promoting IL-6 secretion and JNK pathway signaling. Likewise, constitutively active IKK $\beta$ alters insulin-signaling in hepatocytes, contributing to systemic insulin resistance and glucose intolerance. In fact, NEMO (IKK $\gamma$ ) deficient mice are protected from diet-induced obesity, glucose intolerance, and insulin resistance, suggesting that NEMO expression is required for development of obesity-induced insulin resistance. Moreover, studies suggest that during the onset of insulin resistance, NF-kB promotes $\beta$ cell growth to compensate for the systemic lowered response to insulin [64]. Besides being involved in insulin resistance development and progression, NF-kB proinflammatory pathways contribute to endothelial dysfunction and vascular disease associated with MetS [62••]. Indeed, many genes driving the formation of atherosclerotic plaques are NF-kB targets. The NFkB nuclear absence in macrophages composing atherosclerotic lesions [65] and the abrogated expression of adhesion molecules as 

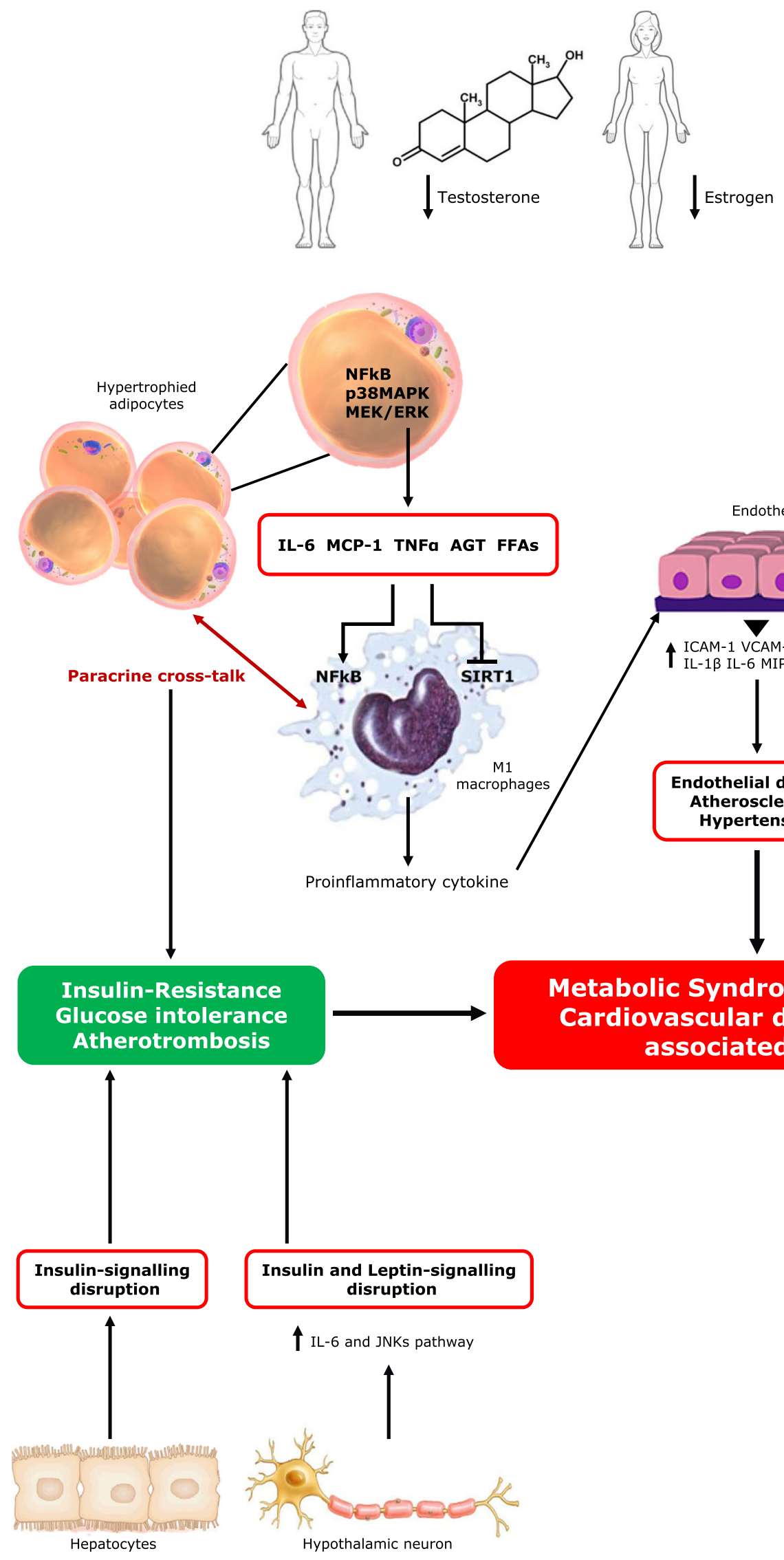

IKK $\beta$ constitutive expression 
ICAM1 and VCAM1, as well as the reduced expression of TNF $\alpha$, IL-1 $\beta$, IL-6, MIP- $1 \alpha$, and MCP-1 in NEMO-deficient endothelial cells, [66] support the finding that NF-kB signaling contributes to the development of vascular damage. Moreover, it has been suggested that NF-kB targets mediate lipid ingestion by macrophage scavenger receptors and foam cell biogenesis [62••].

Interestingly, the AR is also an NF-KB target gene [67••]. Although many authors have considered the AR gender related contribution to adipose tissue to be pathophysiological and cardiovascular risks, there is still much to understand about its cross-talk with NF-kB signaling pathway. The relationship between AR and NF-kB might explain at least in part the pathophysiological mechanism by which androgen dysregulation contributes to the development and progression of metabolic syndrome and hypertension.

\section{Conclusions}

All data we have discussed suggest a similar effect of androgens on increasing the risk of hypertension in both men and women. Androgen deficiency, by increasing visceral obesity and contributing to adipocyte and endothelial dysfunction, seems to be a major determinant of the increased prevalence of hypertension in men but also in women particularly in the postmenopausal period when the protective effect of estrogens has ended. Molecular mechanisms are unclear but increased activation of NF-Kb in a state of reduced occupation of AR may be an important pathway involved in the pathogenesis of the endothelial dysfunction. The NF-kB signaling may also suppress brown adipogenesis leading to the enlargement of white adipocytes. Many more studies will be necessary to clarify the molecular mechanisms linking androgen deficiency with the increased risk of hypertension.

\section{Compliance with Ethics Guidelines}

Conflict of Interest The authors declare that they have no conflict of interest.

Human and Animal Rights and Informed Consent This article does not contain any studies with human or animal subjects performed by any of the authors.

\section{References}

Papers of particular interest, published recently, have been highlighted as:

- Of Importance

• Of Major Importance

1. Maranon R, Reckelhoff JF. Sex and gender differences in control of blood pressure. Clin Sci (Lond). 2013;125(7):311-8.
2. Himmelmann A, Svensson A, Hansson L. Influence of sex on blood pressure and left ventricular mass in adolescents: the hypertension in pregnancy offspring study. J Hum Hypertens. 1994;8(7): 485-90.

3. Stamler J, Stamler R, Riedlinger WF, Algera G, Roberts RH. Hypertension screening of 1 million Americans. Community hypertension evaluation clinic (CHEC) program, 1973 through 1975. JAMA. 1976;235(21):2299-306.

4. Yanes LL, Reckelhoff JF. A new piece in the hypertension puzzle: central blood pressure regulation by sex steroids. Am J Physiol Heart Circ Physiol. 2009;297(5):H1583-4.

5. Reckelhoff JF, Roman RJ. Androgens and hypertension: role in both males and females? Hypertension. 2011;57(4):681-2. The study explores the potential mechanisms by which androgens could increase BP and why prevalence of hypertension in men is greater than in women during the reproductive age while incidence of hypertension increases in women until it exceeds that in men.

6. Festa A, D'Agostino R Jr, Howard G, Mykkänen L, Tracy RP, Haffner SM. Chronic subclinical inflammation as part of the insulin resistance syndrome: the insulin resistance atherosclerosis study (IRAS). Circulation. 2000;102(1):42-7.

7. Meigs JB, Hu FB, Rifai N, Manson JE. Biomarkers of endothelial dysfunction and risk of type 2 diabetes mellitus. JAMA. 2004;291(16):1978-86.

8. Salminen A, Hyttinen JM, Kaarniranta K. AMP-activated protein kinase inhibits NF- $\mathrm{kB}$ signaling and inflammation: impact on healthspan and lifespan. J Mol Med (Berl). 2011;89(7):667-76.

9. Odegaard JI, Chawla A. Pleiotropic actions of insulin resistance and inflammation in metabolic homeostasis. Science. 2013;339(6116): $172-7$.

10. Cai JJ, Wen J, Jiang WH, Lin J, Hong Y, Zhu YS. Androgen actions on endothelium functions and cardiovascular diseases. J Geriatr Cardiol. 2016;13(2):183-96.

11. Kienitz T, Quinkler M. Testosterone and blood pressure regulation. Kidney Blood Press Res. 2008;31(2):71-9.

12. Chen YF, Naftilan AJ, Oparil S. Androgen-dependent angiotensinogen and renin messenger RNA expression in hypertensive rats. Hypertension. 1992;19(5):456-63.

13. Ellison KE, Ingelfinger JR, Pivor M, Dzau VJ. Androgen regulation of rat renal angiotensinogen messenger RNA expression. J Clin Invest. 1989;83(6):1941-5.

14. Hestiantoro A, Swaab DF. Changes in estrogen receptor-alpha and beta in the infundibular nucleus of the human hypothalamus are related to the occurrence of Alzheimer's disease neuropathology. J Clin Endocrinol Metab. 2004;89(4):1912-25.

15. Sartori-Valinotti JC, Iliescu R, Fortepiani LA, Yanes LL, Reckelhoff JF. Sex differences in oxidative stress and the impact on blood pressure control and cardiovascular disease. Clin Exp Pharmacol Physiol. 2007;34(9):938-45.

16. Vikan T, Johnsen SH, Schirmer H, Njølstad I, Svartberg J. Endogenous testosterone and the prospective association with carotid atherosclerosis in men: the Tromsø study. Eur J Epidemiol. 2009;24(6):289-95.

17. Laughlin GA, Barrett-Connor E, Bergstrom J. Low serum testosterone and mortality in older men. J Clin Endocrinol Metab. 2008;93(1):68-75.

18. Dixit KCS, Wu J, Smith LB, Hadoke PWF, Wu FCW. Androgens and coronary artery disease. In: De Groot LJ, Chrousos G, Dungan K, Feingold KR, Grossman A, Hershman JM, Koch C, Korbonits M, McLachlan R, New M, Purnell J, Rebar R, Singer F, Vinik A, editors. Endotext [internet]. South Dartmouth (MA): MDText.com, Inc.; 2000-2015.

19. Moulana M, Lima R, Reckelhoff JF. Metabolic syndrome, androgens, and hypertension. Curr Hypertens Rep. 2011;13(2):158-62. 
20. Liu PY, Death AK, Handelsman DJ. Androgens and cardiovascular disease. Endocr Rev. 2003;24(3):313-40.

21. Mah PM, Wittert GA. Obesity and testicular function. Mol Cell Endocrinol. 2010;316(2):180-6.

22. Mårin P, Holmäng S, Gustafsson C, Jönsson L, Kvist H, Elander A, Eldh J, Sjöström L, Holm G, Björntorp P. Androgen treatment of abdominally obese men. Obes Res. 1993;1(4):245-51.

23. Zitzmann M. Mechanisms of disease: pharmacogenetics of testosterone therapy in hypogonadal men. Nat Clin Pract Urol. 2007;4(3): $161-6$.

24. Reckelhoff JF, Yanes LL, Iliescu R, Fortepiani LA, Granger JP. Testosterone supplementation in aging men and women: possible impact on cardiovascular-renal disease. Am J Physiol Renal Physiol. 2005;289(5):F941-8.

25. Yanes LL, Sartori-Valinotti JC, Iliescu R, Romero DG, Racusen LC, Zhang H, Reckelhoff JF. Testosterone-dependent hypertension and upregulation of intrarenal angiotensinogen in Dahl saltsensitive rats. Am J Physiol Renal Physiol. 2009;296(4):F771-9.

26.• Navarro G, Allard C, Xu W, Mauvais-Jarvis F. The role of androgens in metabolism, obesity, and diabetes in males and females. Obesity (Silver Spring). 2015;23(4):713-9. This review discusses the possibility that the effects of androgens on metabolic syndrome and its sequelae may differ between males and females.

27. Francomano D, Ilacqua A, Bruzziches R, Lenzi A, Aversa A. Effects of 5-year treatment with testosterone undecanoate on lower urinary tract symptoms in obese men with hypogonadism and metabolic syndrome. Urology. 2014;83(1):167-73. This study investigates the effects of TRT during 5 years of treatment for hypogonadism associated with metabolic syndrome and its impact on urinary function and symptoms.

28. Collins L, Basaria S. Adverse effects of androgen deprivation therapy in men with prostate cancer: a focus on metabolic and cardiovascular complications. Asian J Androl. 2012;14(2):222-5.

29.• Choi SM, Kam SC. Metabolic effects of androgen deprivation therapy. Korean J Urol. 2015;56(1):12-8. In this study metabolic and cardiovascular complications of androgen deprivation therapy (ADT) are evaluated. ADT, the main treatment method for metastatic prostate cancer, increases the risk for cardiovascular events.

30. Hakimian P, Blute M Jr, Kashanian J, Chan S, Silver D, Shabsigh R. Metabolic and cardiovascular effects of androgen deprivation therapy. BJU Int. 2008;102(11):1509-14.

31. Malkin CJ, Pugh PJ, Jones RD, Kapoor D, Channer KS, Jones TH. The effect of testosterone replacement on endogenous inflammatory cytokines and lipid profiles in hypogonadal men. J Clin Endocrinol Metab. 2004;89(7):3313-8.

32. Cohen PG. Obesity in men: the hypogonadal-estrogen receptor relationship and its effect on glucose homeostasis. Med Hypotheses. 2008;70(2):358-60.

33. Isidori AM, Caprio M, Strollo F, Moretti C, Frajese G, Isidori A, Fabbri A. Leptin and androgens in male obesity: evidence for leptin contribution to reduced androgen levels. J Clin Endocrinol Metab. 1999;84(10):3673-80.

34.• Dubois V, Laurent MR, Jardi F, Antonio L, Lemaire K, Goyvaerts L, Deldicque L, Carmeliet G, Decallonne B, Vanderschueren D, Claessens F. Androgen deficiency exacerbates high-fat diet-induced metabolic alterations in male mice. Endocrinology. 2016;157(2): 648-65. In this paper the importance of a healthy diet in a clinical context of androgen deficiency is stressed. It may have implications for the prevention of metabolic alterations in hypogonadal men.

35. Salam R, Kshetrimayum AS, Keisam R. Testosterone and metabolic syndrome: the link. Indian J Endocrinol Metab. 2012;16(Suppl 1):S12-9.

36. Yanes LL, Reckelhoff JF. Postmenopausal hypertension. Am J Hypertens. 2011;24(7):740-9.
37. Weiner CP, Lizasoain I, Baylis SA, Knowles RG, Charles IG, Moncada S. Induction of calcium-dependent nitric oxide synthases by sex hormones. Proc Natl Acad Sci U S A. 1994;91(11):5212-6.

38. Nickenig G, Böhm M. Interaction between insulin and AT1 receptor. Relevance for hypertension and arteriosclerosis. Basic Res Cardiol. 1998;93(Suppl 2):135-9.

39. Xue B, Singh M, Guo F, Hay M, Johnson AK. Protective actions of estrogen on angiotensin II-induced hypertension: role of central nitric oxide. Am J Physiol Heart Circ Physiol. 2009;297(5): H1638-46.

40. Huang CK, Lee SO, Chang E, Pang H, Chang C. Androgen receptor (AR) in cardiovascular diseases. J Endocrinol. 2016;229(1):R1R16. This paper underlines that androgen deficiency causes elevated lipid accumulation enhancing atherosclerosis, and that AR plays an important role in contributing to obesity and insulin/leptin resistance to increase the metabolic syndrome.

41. Lobo RA, Carmina E. The importance of diagnosing the polycystic ovary syndrome. Ann Intern Med. 2000;132:989-93.

42. Carmina E, Napoli N, Longo RA, Rini GB, Lobo RA. Metabolic syndrome in polycystic ovary syndrome (PCOS): lower prevalence in southern Italy than in the USA and the influence of criteria for the diagnosis of PCOS. Eur J Endocrinol. 2006;154:141-5.

43. Goodman NF, Cobin RH, Futterweit W, Glueck JS, Legro RS, Carmina E. American Association of Clinical Endocrinologists, American College of Endocrinology, and androgen excess and PCOS society disease state clinical review: guide to the best practices in the evaluation and treatment of polycystic ovary syndrome - part 1. Endocr Pract. 2015;21(11):1291-300. A review of recent findings that clarifies the clinical practice for PCOS treatment, considering metabolic alteration, insulin resistance and cardiovascular risk.

44. Jovanovic VP, Carmina E, Lobo RA. Not all women diagnosed with PCOS share the same cardiovascular risk profiles. Fertil Steril. 2010;94:826-32.

45. Guastella E, Longo RA, Carmina E. Clinical and endocrine characteristics of the main PCOS phenotypes. Fertil Steril. 2010;94: 2197-201.

46. Carmina E. Obesity, Adipokines and metabolic syndrome in polycystic ovary syndrome. Front Horm Res. 2013;40:40-50.

47. Sarray S, Madan S, Saleh LR, Mahmoud N, Almawi WY. Validity of adiponectin-to-leptin and adiponectin-to-resistin ratios as predictors of polycystic ovary syndrome. Fertil Steril. 2015;104(2):460 6. This study shows that adiponectin/leptin and adiponectin/ resistin ratios play an important role in metabolic syndrome and hypertension in women affected with PCOS.

48. Vasan RS, Larson MG, Leip EP, Evans JC, O’Donnell CJ, Kannel WB, Levy D. Impact of high-normal blood pressure on the risk of cardiovascular disease. N Engl J Med. 2001;345(18):1291-7.

49. Ong KL, Tso AW, Lam KS, Cheung BM. Gender difference in blood pressure control and cardiovascular risk factors in Americans with diagnosed hypertension. Hypertension. 2008;51(4):1142-8.

50. Wiinberg N, Høegholm A, Christensen HR, Bang LE, Mikkelsen KL, Nielsen PE, Svendsen TL, Kampmann JP, Madsen NH, Bentzon MW. 24-h ambulatory blood pressure in 352 normal Danish subjects, related to age and gender. Am J Hypertens. 1995;8(10 Pt 1):978-86.

51. Laughlin GA, Barrett-Connor E. Sexual dimorphism in the influence of advanced aging on adrenal hormone levels: the rancho Bernardo study. J Clin Endocrinol Metab. 2000;85(10):3561-8.

52. Labrie F, Bélanger A, Cusan L, Gomez JL, Candas B. Marked decline in serum concentrations of adrenal C19 sex steroid precursors and conjugated androgen metabolites during aging. JCEM. 1997;82:2386-92. 
53. Piltonen T, Koivunen R, Ruokonen A, Tapanainen JS. Ovarian agerelated responsiveness to human chorionic gonadotropin. JCEM. 2003;88:3327-32.

54. Davison SL, Bell R, Donath S, Montalto JG, Davis SR. Androgen levels in adult females: changes with age, menopause and oophorectomy. J Clin Endocrinol Metab. 2005;90:3847-53.

55. Carmina E, Campagna AM, Lobo RA. A 20-year follow-up of young women with polycystic ovary syndrome. Obstet Gynecol. 2012;119:263-9.

56.• Rutkowski K, Sowa P, Rutkowska-Talipska J, Kuryliszyn-Moskal A, Rutkowski R. Dehydroepiandrosterone (DHEA): hypes and hopes. Drugs. 2014;74(11):1195-207. This paper underlines that in women after menopause the relative androgen deficiency is related to metabolic dysfunction and visceral fat depot increasing CVD

57. Carmina E, Chu MC, Moran C, Tortoriello D, Vardhana P, Tena G, Preciado R, Lobo R. Subcutaneous and omental fat expression of adiponectin and leptin in women with polycystic ovary syndrome. Fertil Steril. 2008;89:642-8.

58. Ely DL, Salisbury R, Hadi D, Turner M, Johnson ML. Androgen receptor and the testes influence hypertension in a hybrid rat model. Hypertension. 1991;17(6 Pt 2):1104-10.

59. Rayet B, Gélinas C. Aberrant rel/nfkb genes and activity in human cancer. Oncogene. 1999;18(49):6938-47.

60. Pentikäinen V, Suomalainen L, Erkkilä K, Martelin E, Parvinen M, Pentikäinen MO, Dunkel L. Nuclear factor-kappa B activation in human testicular apoptosis. Am J Pathol. 2002;160(1):205-18.

61. Baud V, Karin M. Is NF-kappaB a good target for cancer therapy? Hopes and pitfalls. Nat Rev Drug Discov. 2009;8(1):33-40.
62.•• Baker RG, Hayden MS, Ghosh S. NF-kB, inflammation, and metabolic disease. Cell Metab. 2011;13(1):11-22. In this review the role of NF-kB in endothelial dysfunction and foam cells biogenesis in metabolic syndrome is discussed.

63. Suganami T, Tanimoto-Koyama K, Nishida J, Itoh M, Yuan X, Mizuarai S, Kotani H, Yamaoka S, Miyake K, Aoe S, Kamei Y, Ogawa Y. Role of the toll-like receptor 4/NF-kappaB pathway in saturated fatty acid-induced inflammatory changes in the interaction between adipocytes and macrophages. Arterioscler Thromb Vasc Biol. 2007;27(1):84-91.

64. Chang I, Kim S, Kim JY, Cho N, Kim YH, Kim HS, Lee MK, Kim KW, Lee MS. Nuclear factor kappaB protects pancreatic beta-cells from tumor necrosis factor-alpha-mediated apoptosis. Diabetes. 2003;52(5):1169-75.

65. Brand K, Page S, Rogler G, Bartsch A, Brandl R, Knuechel R, Page M, Kaltschmidt C, Baeuerle PA, Neumeier D. Activated transcription factor nuclear factor-kappa $\mathrm{B}$ is present in the atherosclerotic lesion. J Clin Invest. 1996;97(7):1715-22.

66. Gareus R, Kotsaki E, Xanthoulea S, van der Made I, Gijbels MJ, Kardakaris R, Polykratis A, Kollias G, de Winther MP, Pasparakis M. Endothelial cell-specific NF-kappaB inhibition protects mice from atherosclerosis. Cell Metab. 2008;8(5):372-83.

67.• Zhang L, Altuwaijri S, Deng F, Chen L, Lal P, Bhanot UK, Korets R, Wenske S, Lilja HG, Chang C, Scher HI, Gerald WL. NFkappaB regulates androgen receptor expression and prostate cancer growth. Am J Pathol. 2009;175(2):489-99. The study concerns the implications of the transcription factor NF-kB in tumorigenesis and how it may promote $\mathrm{AR}$ transcription activation. 